\title{
LAYANAN KONSELING ATLET: PENGABDIAN MASYARAKAT UNTUK PERSATUAN BULUTANGKIS JAYA RAYA
}

\author{
Gita Widya Laksmini Soerjoatmodjo ${ }^{1)}$, Clara Moningka ${ }^{2)}$ \\ dan Yulius Fransisco Angkawijaya ${ }^{3)}$ \\ 1) Program Studi Psikologi Universitas Pembangunan Jaya \\ 2) Program Studi Psikologi Universitas Pembangunan Jaya \\ 3) Program Studi Psikologi Universitas Pembangunan Jaya \\ Surel: (gita.soerjoatmodjo@upj.ac.id)
}

\begin{abstract}
ABSTRAK
Latar belakang kegiatan pengabdian masyarakat antara Program Studi Psikologi Universitas Pembangunan Jaya (PSI UPJ) dan Persatuan Bulutangkis Jaya Raya (PB Jaya Raya) ini adalah sebagai berikut. Agar dapat berprestasi optimal, maka atlet tak hanya perlu memiliki kemampuan fisik dan teknik yang prima, tetapi juga membutuhkan keterampilan psikologis (psychological skills). Hal ini terjadi pada dalam cabang olahraga bulutangkis yang butuh pembinaan sejak remaja. Tujuan konseling untuk atlet adalah mengembangkan sembilan keterampilan mental untuk atlet mulai dari sikap sampai konsentrasi. Metode yang digunakan adalah riset aksi (action research) yang mencakup focus group discussion, wawancara, konseling kelompok, observasi situasi pertandingan sampai konseling individual. Kegiatan ini melibatkan pelatih teknik, pelatih fisik, guru, pengurus asrama dan atlet putra dan putri usia 12-18 tahun dari cabang tunggal, ganda putra dan putri serta campuran Sekolah Bulutangkis PB Jaya Raya serta dosen dan mahasiswa PSI UPJ. Kolaborasi ini dipayungi Memorandum of Understanding antar dua institusi di bawah naungan Kelompok Usaha Pembangunan Jaya. Kegiatan sepanjang Maret-September 2017 ini menghasilkan program konseling, 2 artikel di media elektronik Info Bintaro dan Buletin Konsorsium Psikologi Ilmiah Nusantara, 1 publikasi Jurnal Widyakala UPJ Vol 4 No 1 Tahun 2017 dan 1 Modul Konseling untuk Atlet sebagai buku ber-ISBN.
\end{abstract}

Kata Kunci: psikologi olahraga, atlet, bulutangkis, keterampilan mental, konseling

\begin{abstract}
The background of this community service conducted by Department of Psychology Universitas Pembangunan Jaya (PSI UPJ) and Jaya Raya Badminton Club (PB Jaya Raya) is as follow. For optimum achievement, athletes should have excellent physical, technical and psychological skills. This applies as well in badminton, since this sport requires training as early as in adolescence. The objective of this counselling for athlete program is to develop nine mental skills, comprising from attitude to concentration. Method used is action research - from focus group discussion, interviews, group counselling, observation during competition and individual counselling. This activity involves technical and physical coaches, teachers, boarding school manager and 12-18 years-old male and female athlete from single, double and mixed-double categories; as well as lectures and students. This collaboration is made possible under the Memorandum of Understanding between two institutions both are part of the family of Pembangunan Jaya Group. From March to September 2017, this community service results in the implementation of a counselling program, 2 articles of Info Bintaro and Buletin Konsorsium Psikologi Ilmiah Nusantara electronic media, 1 publication in Widyakala UPJ journal of Vol 4 No 12017 and 1 Counselling for Athletes Module as ISBN-registered book publication.
\end{abstract}

Keywords: sport psychology, athletes, badminton, mental skills, counselling 


\section{PENDAHULUAN}

Latar belakang tulisan ini adalah sebagai berikut. Sejak 17 Juli 1976, Persatuan Bulutangkis (PB) Jaya Raya menjadi salah satu klub bulutangkis elit di Indonesia. Keberhasilan PB Jaya Raya mengharumkan nama bangsa di kancah internasional dicatat dengan tinta emas dalam sejarah Indonesia (Wondowisnowo, 2016). Pada 15 September 2016, di ulang tahun ke-40, PB Jaya Raya meresmikan Gedung Olah Raga (GOR) baru di Bintaro Jaya oleh Menteri Pemuda dan Olahraga Imam Nahrawi bersama pendiri Kelompok Usaha Pembangunan Jaya Ir. Ciputra. Seiring komitmen tersebut, perhatian terhadap prestasi pun serta merta meningkat (Kompas, 2016)

Permasahan yang diangkat dalam tulisan ini adalah sebagai berikut. Tugas utama atlet adalah bertanding dan performa atlet merupakan hasil dari stamina, kekuatan, fleksibilitas, koordinasi, keterampilan dan kemampuan bermain (Gunarsa, 2008). Sementara studi pustaka menunjukkan bahwa atlet tak cuma butuh keterampilan fisik dan teknik tetapi juga keterampilan psikologis. Keterampilan psikologis (psychological skills) merupakan perilaku hasil belajar untuk dimanfaatkan atlet agar berprestasi, antara lain kepercayaan diri dan motivasi (Anderson, Miles, Mahoney \& Robinson, 2002). Temuan terhadap atlet PB Jaya Raya menyimpulkan bahwa belum semua atlet memiliki keterampilan psikologis ini, sebagaimana tampak pada masih lemahnya mencapai kematangan emosi yang mereka butuhkan untuk mengatasi stres (Putri, 2016). Keterampilan psikologis terbukti penting melahirkan sang juara (Soerjoatmodjo, Moningka \& Angkawijaya, 2018). Hal ini yang menjadi tujuan pengabdian yaitu menjawab kebutuhan peningkatan keterampilan psikologis atlet PB Jaya Raya agar mereka dapat berprestasi optimal.

\section{TINJAUAN PUSTAKA}

Segala upaya menghasilkan atlet berprestasi termasuk dalam psikologi olahraga. Psikologi olahraga bertujuan mengidentifikasi faktor psikologis yang mempengaruhi partisipasi dan performa individu di bidang olahraga serta intervensi peningkatan prestasi dan pengembangan pribadi (Williams \& Straub, 2010). Salah satu bentuknya adalah penguasaan keterampilan psikologis oleh atlet.

Karakteristik atlet yang memiliki keterampilan psikologis antara lain mampu melepaskan stres melalui kegiatan fisik, mampu rileks tanpa tergantung pada perintah pelatih, mampu melakukan kegiatan yang nyaman dan menenangkan bagi dirinya, mampu menguasai teknik dan strategi pertandingan, mampu mengembangkan strategi mental, mampu membangun kepercayaan tinggi dan mampu memberikan makna yang proporsional terhadap kekalahan (Putri, 2016).

Hal ini yang perlu ditingkatkan pada atlet PB Jaya Raya Hal ini muncul dalam Soerjoatmodjo, Moningka dan Angkawijaya (2017) yang mengungkapkan bahwa saat kalah bertanding, atlet PB Jaya Raya merasa tidak percaya, sedih, minder, kecewa, malu, dongkol, frustrasi, merasa diri sendiri bagaikan pecundang, stres, takut, merasa gagal, tidak bisa tidur, tidak nafsu makan, ingin menyendiri sampai ingin menyerah.

Penelitian lain menunjukkan potret yang tak jauh berbeda. Penelitian terhadap 50 pelajar atlet bulu tangkis di GOR Ragunan menguraikan ada empat stressor atau sumber stres yakni (1) physical stressor atau tuntutan fisiologis terhadap fisik atlet, (2) social stressor atau sumber stres yang timbul dari interaksi individu dengan individu lain, (3) psychological 
stressor atau sumber stres yang timbul dari rasa frustrasi, kecemasan maupun konflik, dan (4) endemic stressor atau sumber stres yang tidak dapat dihindari atau disebabkan oleh faktor di luar kendali individu seperti duka cita (Widiani, 2011).

Keterampilan psikologis menjadi penting untuk diperhatikan oleh PB Jaya Raya. Prestasi utama yang pernah dicapai PB Jaya Raya adalah adalah 3 medali emas Olimpiade, 8 medali emas Kejuaraan Dunia, 12 kali juara All England, 8 kali juara Piala Thomas, 3 kali juara Piala Uber, 1 kali Piala Sudirman, 13 medali emas Kejuaraan Asia, 7 medali emas Asian Games, dan 59 medali emas SEA Games (Wondowisnowo, 2016). Sejumlah atlet Jaya Raya berhasil membuahkan medali emas di tingkat Olimpiade yaitu Susi Susanti pada Olimpiade Barcelona 1992, Candra Wijaya/Tony Gunawan pada Olimpiade Sydney 2000 dan Markis Kido/Hendra Setiawan pada Olimpiade Beijing 2008 (Kompas, 2016). Capaian inilah yang perlu untuk terus dipertahankan.

Salah satu cara mempertahankan prestasi adalah meningkatkan fasilitas. GOR baru memiliki fasilitas meliputi 16 lapangan dengan luas total 4.583 meter persegi dalam kompleks seluas 1.3 hektar dengan tribun berkapasitas 500 penonton. GOR tersebut juga dilengkapi sekolah dengan 6 kelas, 3 ruang lab dan sejumlah ruang administrasi kependidikan dengan kurikulum 2013 setara SMP dan SMA yang disusun Sekolah Pembangunan Jaya (SPJ). Para atlet usia 12-18 tahun tinggal di asrama 3 lantai, masing-masing terdiri dari 25 ruang untuk atlet putra dan putri, dilengkapi sarana penunjang lainnya seperti ruang makan, dapur dan laundry (Bulutangkis.com, 2016). Disinilah mereka berlatih selama 4 hari dalam seminggu, dimulai dari pukul 05.00-19.00 WIB. Jadwal keseharian ini diawal dengan latihan fisik di pagi hari, kegiatan akademik di Sekolah Badminton, istirahat sejenak kemudian kembali bergelut dengan raket sampai malam. Para atlet tersebut kemudian berlatih dan bertanding dalam lima partai yakni (1) tunggal putra, (2) tunggal putri, (3) ganda putra, (4) ganda putri, dan (5) ganda campuran. Atlet bulutangkis menjalani latihan demi mencapai kondisi fisik yang salah satunya ditandai dengan volume oksigen pada paru-paru (Rana, 2012). Selain itu, atlet juga menjalani latihan teknik agar menguasai pukulan service, lob, dropshot, smash, backhand, drive sampai netting agar shuttlecock dapat diarahkan ke tempat yang sulit dijangkau dijangkau lawan (Putri, 2016).

Pembinaan sejak dini secara sistematis dan terkonsentrasi ini penting mengingat bulutangkis merupakan cabang olahraga yang efektif dikembangkan sejak usia 11-12 tahun dan diharapkan mencapai puncak pada usia 20-25 tahun (Putri, 2016). Secara umum, atlet bulutangkis dikategorisasikan berdasarkan gender, usia dan cabang, sebagaimana tercermin pada Tabel 1 berikut.

\section{Tabel 1. Kategorisasi Atlet Bulutangkis Berdasarkan Usia}

\begin{tabular}{l|c}
\hline \multicolumn{1}{c|}{ Usia } & Kategori \\
\hline 10 tahun ke bawah & Anak \\
\hline $10-13$ tahun & Pemula \\
\hline $13-15$ tahun & Remaja \\
\hline $15-19$ tahun & Taruna \\
\hline 19 tahun ke atas & Dewasa \\
\hline
\end{tabular}

Dapat dilihat bahwa kelompok usia tersebut tergolong dalam kelompok anak, remaja sampai dewasa. Maka perlu diingat, seraya meraih prestasi, mereka juga menjalani transisi antara kelompok usia dengan tugas perkembangan berbeda-beda. Santrock (2011) menjelaskan 
bahwa sepanjang periode tersebut, terjadi perubahan biologis, kognitif dan sosioemosional dalam upaya menemukan jati diri dan arah mereka dalam menjalani keseharian. Keterampilan psikologis menjadi penting dalam masa transisi ini.

Tanpa keterampilan psikologis, atlet dapat dikuasai hal-hal yang mengganggu seperti masalah penyesuaian diri, stres, rasa cemas berlebihan dan sebagainya, yang mengakibatkan konsentrasi saat bertanding berpotensi terganggu sehingga berakibat pada atlet yang kurang optimal mencapai prestasi. Oleh karena itu, atlet pada usia-usia tersebut membutuhkan dukungan sosial (social support) yaitu adanya orang lain di sekitar diri mereka yang dapat memberikan perasaan nyaman, memberikan perhatian pada kesejahteraannya, menaruh kepercayaan pada kemampuan mereka dan memberikan bantuan informasi positif yang memunculkan rasa tenang (Putri, 2016). Para atlet butuh bantuan agar dapat mengendalikan cara berpikir dan belajar yang memampukan mereka untuk mengolah emosi secara konstruktif.

Salah satu cara adalah konseling. Konseling adalah proses dialog yang terbuka, jujur dan bermakna antara konselor dan klien atau konseli dengan tujuan membantu klien mengatasi masalah dan meraih kesempatan melalui penerimaan atas persepsi dan perasaan tanpa menghakimi atau prasangka (Anshel, 2003). Konseling dirancang membantu konseli memahami masalah sehingga diperoleh insight yang membantunya menyelesaikan masalah serta menentukan langkah selanjutnya (Thompson, Rudoph \& Henderson, 2004). Melalui konseling, atlet diajak berperan serta memahami keadaan atau situasi yang mereka alami. Moningka (2017) menyarankan juga konseling dapat mengasah keterampilan hidup (life skills). Sayangnya hingga saat ini, PB Jaya Raya belum menyediakan layanan konseling bagi atlet-atletnya.

\section{BAHAN DAN METODE}

Pendekatan dan metode pelaksanaan adalah riset aksi (action research) karena cara inilah yang bertujuan memberdayakan subyek dapat manfaat sebesar-besarnya, ketimbang mendudukkan mereka sebagai subyek pasif dalam eksperimen terkontrol (Giles, 2008). Sebelum pelaksanaan, dilakukanlah pengukuran kebutuhan (need assessment) dengan proses pengukuran cepat (Rapid Assessment Process/RAP) yakni penggalian informasi kualitatif secara intensif dan berbasis pada tim menggunakan triangulasi, analisis data secara iteratif dan pengumpulan data tambahan untuk secara cepat membangun pemahaman dasar tentang satu situasi dari sudut pandang pelaku (Beebe, 2001).

Hal tersebut dilakukan Soerjoatmodjo, Kaihatu, Moningka dan Angkawijaya (2017) dengan mengumpulkan data primer dan sekunder melibatkan pelatih teknik, pelatih fisik, guru, pengurus asrama dan atlet PB Jaya Raya serta dosen dan mahasiswa Program Studi Psikologi UPJ (PSI UPJ). Caranya dengan focus group discussion dan wawancara dilanjutkan dengan workshop perkenalan yang dilakukan sepanjang Maret 2017, seperti tampak pada Gambar 1 di bawah ini. 


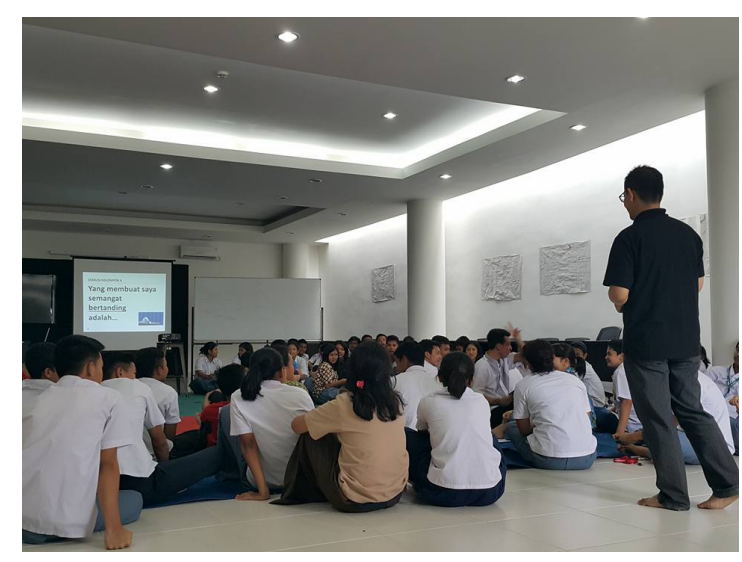

\section{Gambar 1. Workshop Perkenalan, PB Jaya Raya, Maret 2017}

Variabel yang diamati adalah keterampilan mental atlet, dimana fokus konseling adalah membantu atlet mengembangkan keterampilan mental yang dibutuhkan dalam keseharian, saat berlatih dan saat bertanding. Proses konseling dilakukan kolaboratif bersama dosen dan mahasiswa. Tiga orang dosen PSI UPJ berkualifikasi sebagai psikolog melakukan konseling pada Maret 2017. Pelibatan mahasiswa dilakukan melalui mata kuliah Observasi dan Wawancara. Dua puluh tiga mahasiswa sebelumnya mendapatkan briefing dan mengobservasi situasi pertandingan pada kompetisi internasional Pembangunan Jaya Raya Yonex Sunrise Junior Grand Prix 2017 11-16 April 2017 seperti tampak pada Gambar 2 di bawah ini.

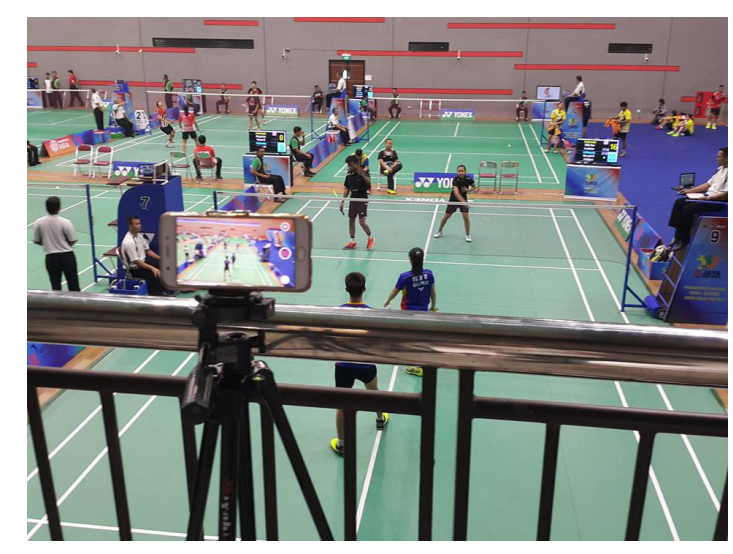

Gambar 2. Observasi Situasi Pertandingan, GOR PB Jaya Raya, April 2017

Secara keseluruhan, pelaksanaan konseling dilakukan Maret-September 2017 baik di PB Jaya Raya maupun di area publik seperti mal dan restoran yang terdapat di bilangan Bintaro, sebagaimana tampak pada Gambar 3 berikut ini. 


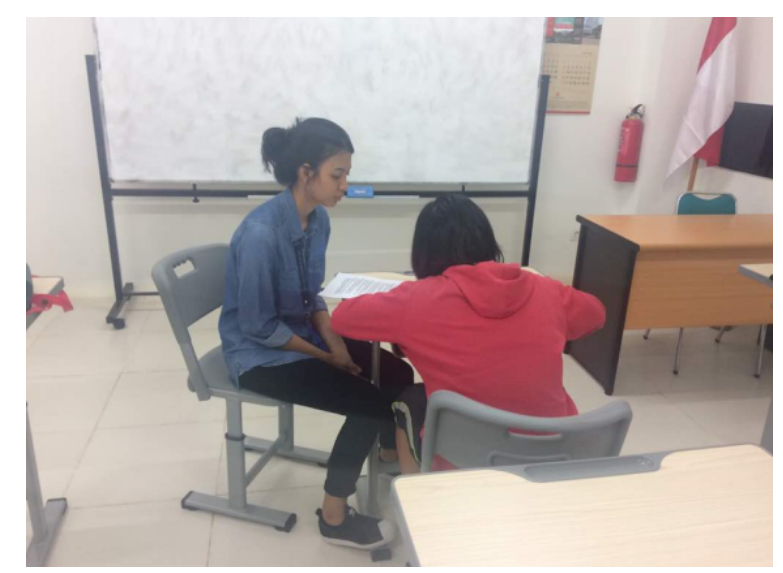

Gambar 3. Konseling, Sekolah PB Jaya Raya, Mei 2017

Alat yang digunakan adalah panduan konseling yang disusun merujuk pada sembilan keterampilan mental dari Lesyk (2007) sebagaimana dapat dilihat pada Tabel 2 berikut.

Tabel 2. Keterampilan Mental Atlet yang Berhasil

\begin{tabular}{|c|c|c|c|c|}
\hline Level & Tingkat & Konteks & Keterampilan & Uraian \\
\hline \multirow[t]{4}{*}{1} & \multirow[t]{4}{*}{$\begin{array}{l}\text { Basic } \\
\text { Skills }\end{array}$} & \multirow[t]{4}{*}{ Keseharian } & Sikap (Attitude) & $\begin{array}{l}\text { Mampu memilih sikap positif terhadap } \\
\text { pilihan untuk berkarir sebagai atlet }\end{array}$ \\
\hline & & & Motivasi (Motivation) & $\begin{array}{l}\text { Mampu mengidentifikasi hal-hal yang } \\
\text { memberi motivasi }\end{array}$ \\
\hline & & & $\begin{array}{l}\text { Tujuan dan Komitmen } \\
\text { (Goals and } \\
\text { Commitment) }\end{array}$ & $\begin{array}{l}\text { Mampu menetapkan target dan } \\
\text { berkomitmen mencapai tujuan }\end{array}$ \\
\hline & & & $\begin{array}{l}\text { Menjalin Hubungan } \\
\text { dengan Orang Lain } \\
\text { (People Skills) }\end{array}$ & $\begin{array}{l}\text { Mampu menempatkan diri dalam sistem } \\
\text { sosial, dapat membangun hubungan } \\
\text { serta efektif mengelola konflik }\end{array}$ \\
\hline \multirow[t]{2}{*}{2} & \multirow[t]{2}{*}{$\begin{array}{l}\text { Prepa- } \\
\text { ratory } \\
\text { Skills }\end{array}$} & \multirow{2}{*}{$\begin{array}{l}\text { Latihan } \\
\text { menjelang } \\
\text { pertan- } \\
\text { dingan }\end{array}$} & $\begin{array}{l}\text { Berbicara dengan Diri } \\
\text { Sendiri (Self Talk) }\end{array}$ & $\begin{array}{l}\text { Mampu berbicara pada diri sendiri } \\
\text { seolah-olah sedang berbicara pada } \\
\text { sahabat }\end{array}$ \\
\hline & & & $\begin{array}{l}\text { Membangun Imajeri } \\
\text { Mental (Mental } \\
\text { Imagery) }\end{array}$ & $\begin{array}{l}\text { Mampu membayangkan diri sendiri } \\
\text { berhasil pada saat bertanding }\end{array}$ \\
\hline \multirow[t]{3}{*}{3} & \multirow[t]{3}{*}{$\begin{array}{l}\text { Perfor- } \\
\text { mance } \\
\text { Skills }\end{array}$} & \multirow{3}{*}{$\begin{array}{l}\text { Unjuk } \\
\text { kemam- } \\
\text { puan saat } \\
\text { bertanding }\end{array}$} & $\begin{array}{l}\text { Mengelola Kecemasan } \\
\text { (Dealing with Anxiety) }\end{array}$ & $\begin{array}{l}\text { Mampu menerima kecemasan sebagai } \\
\text { bagian dari menjalani pertandingan dan } \\
\text { mengetahui cara menurunkannya }\end{array}$ \\
\hline & & & $\begin{array}{l}\text { Mengelola Emosi } \\
\text { (Dealing with } \\
\text { Emotion) }\end{array}$ & $\begin{array}{l}\text { Mampu menerima emosi, } \\
\text { mengungkapkan secara tepat dan } \\
\text { menggunakan emosi untuk } \\
\text { meningkatkan performa }\end{array}$ \\
\hline & & & $\begin{array}{l}\text { Berkonsentrasi } \\
\text { (Concentration) }\end{array}$ & $\begin{array}{l}\text { Mampu mempertahankan konsentrasi, } \\
\text { fokus pada pertandingan }\end{array}$ \\
\hline
\end{tabular}

Secara keseluruhan, setiap konseling dilakukan secara tatap muka dalam durasi 45-90 menit yang kemudian ditranskripsi sepanjang Juni 2017 Transkripsi kemudian ditelaah tim dosen selama Juli-Agustus 2017 untuk memberikan penilaian, yaitu Baik (B), Cukup (C) dan Kurang (K) seperti pada Tabel 3. 
Tabel 3. Tabel Penilaian Keterampilan Mental

\begin{tabular}{l|l|l|l|l}
\hline No & \multicolumn{1}{|c|}{ Keterampilan } & Baik & Cukup & Kurang \\
\hline 1 & Sikap (Attitude) & & & \\
\hline 2 & Motivasi (Motivation) & & & \\
\hline 3 & Tujuan dan Komitmen (Goals and Commitment) & & & \\
\hline 4 & $\begin{array}{l}\text { Menjalin Hubungan dengan Orang Lain } \\
\text { (People Skills) }\end{array}$ & & & \\
\hline 5 & Berbicara dengan Diri Sendiri (Self Talk) & & & \\
\hline 6 & Membangun Imajeri Mental (Mental Imagery) & & & \\
\hline 7 & Mengelola Kecemasan (Dealing with Anxiety) & & & \\
\hline 8 & Mengelola Emosi (Dealing with Emotion) & & & \\
\hline 9 & Berkonsentrasi (Concentration) & & & \\
\hline
\end{tabular}

Penilaian difinalisasi pada September 2017. Analisis data dilakukan deskriptif dengan menghitung frekuensi jumlah penilaian Baik, Cukup dan Kurang untuk sembilan keterampilan mental dengan hasil yang dituangkan dalam grafik, yang dilakukan pada akhir September 2017.

\section{HASIL DAN PEMBAHASAN}

Hasil pengabdian masyarakat adalah sebagai berikut. Total 62 atlet yang mendapat layanan konseling atlet dengan komposisi gender seimbang, seperti pada Gambar 4.

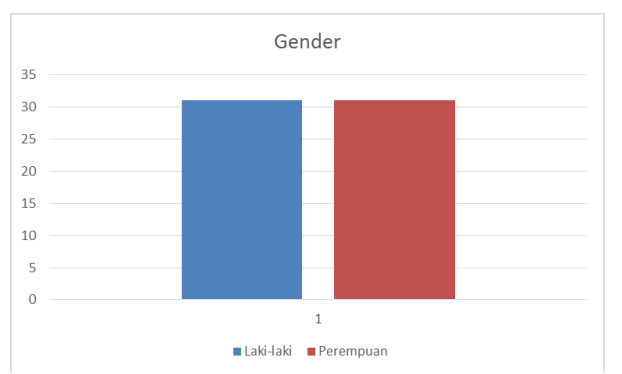

\section{Gambar 4. Gender}

Mayoritas subyek berada di usia remaja, sebagaimana tampak pada Gambar 5 berikut

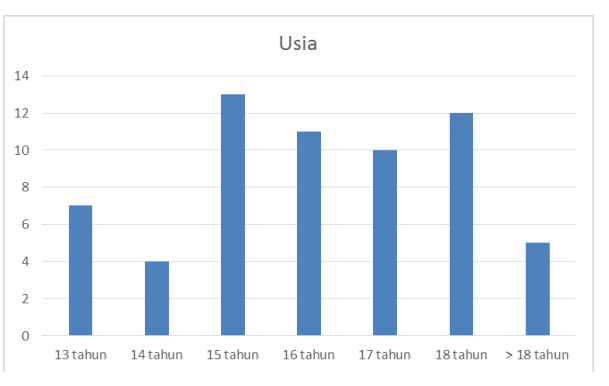

Gambar 5. Usia 
Hasil untuk sembilan keterampilan mental adalah sebagai berikut. Bagian pertama ini menguraikan keterampilan dasar yang dibutuhkan dalam konteks keseharian yaitu sikap, motivasi, tujuan dan komitmen serta keterampilan berhubungan dengan orang lain.

1. Sikap (Attitude)

Atlet dengan sikap baik adalah mereka yang bersikap positif pada pilihan karir sebagai atlet. Sebagian besar mempunyai sikap tersebut seperti pada Gambar 6 berikut.

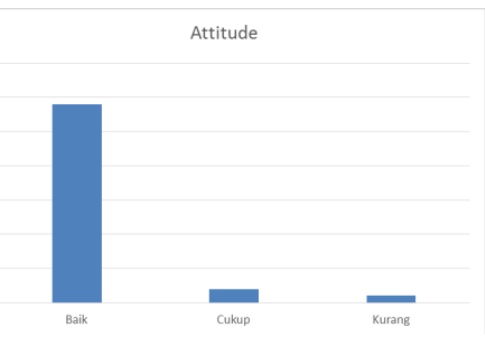

\section{Gambar 6. Sikap}

2. Motivasi (Motivation)

Atlet dengan motivasi baik adalah mereka yang mampu mengidentifikasi hal-hal yang menggerakkannya. Gambar 7 berikut menunjukkan sebagian besar memiliki motivasi baik.

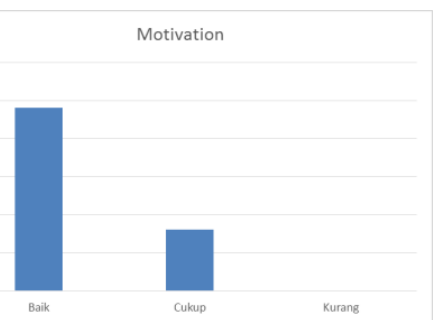

\section{Gambar 7. Motivasi}

3. Tujuan dan Komitmen (Goals and Commitment)

Atlet dengan tujuan dan komitmen baik adalah mereka yang mampu menetapkan target dan berkomitmen memegang tujuan. Sementara sebagian memiliki tujuan dan komitmen yang baik, komposisi mereka dengan tujuan dan komitmen cukup dan kurang kurang lebih setara.

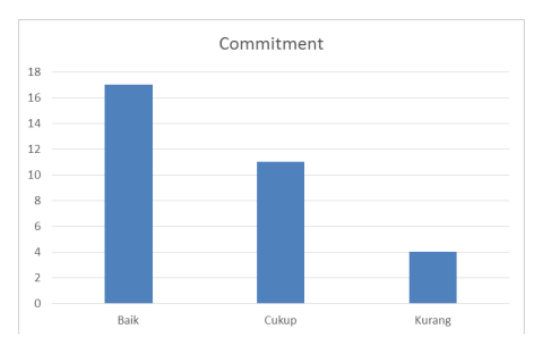

\section{Gambar 8. Tujuan dan Komitmen}

4. Menjalin Hubungan dengan Orang Lain (People Skills) 
Atlet yang dapat menjalin hubungan baik dengan orang lain adalah mereka yang mampu menempatkan diri dalam sistem sosial, membangun hubungan serta efektif mengelola konflik. Sebagian besar memiliki keterampilan baik, hanya saja jika dibandingkan dengan kategori cukup dan kurang, jumlahnya dapat dikatakan setara.

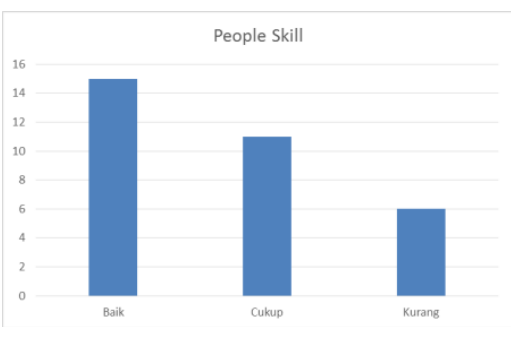

\section{Gambar 9. Menjalin Hubungan dengan Orang Lain}

Dari keempat keterampilan mental tingkat dasar di atas, disimpulkan bahwa untuk konteks keseharian, sebagian besar atlet Jaya Raya punya keterampilan baik.

Bagian berikut menguraikan keterampilan yang dibutuhkan untuk mempersiapkan diri menjelang pertandingan, sebagaimana dipaparkan lebih lanjut berikut ini.

5. Berbicara dengan Diri Sendiri (Self Talk)

Atlet yang dapat bicara dengan diri sendiri adalah mereka yang mampu berbicara seolaholah sedang bercakap-cakap dengan sahabat. Sementara mereka yang mampu dengan baik cukup banyak, mereka yang keterampilannya kurang pun tidak sedikit.

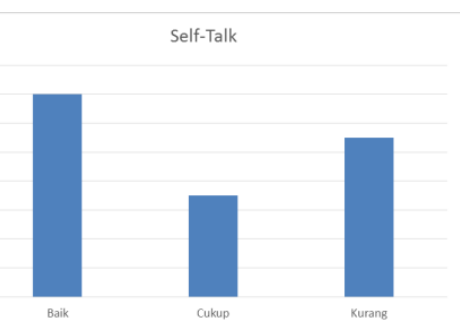

\section{Gambar 10. Berbicara dengan Diri Sendiri}

6. Membangun Imajeri Mental (Mental Imagery)

Atlet yang mampu membangun imajeri mental adalah mereka yang dapat membayangkan diri sendiri berhasil saat bertanding. Dapat dilihat bahwa jummlah mereka yang kurang mampu lebih banyak dibandingkan mereka yang sanggup membangun imajeri mental secara baik.

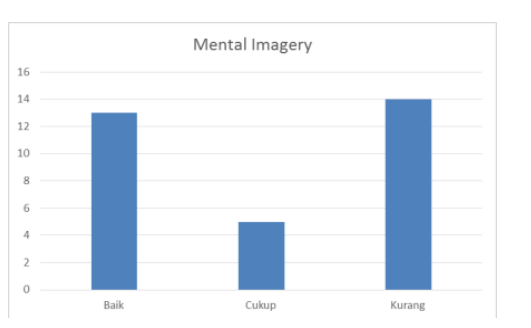




\section{Gambar 11. Membangun Imajeri Mental}

Dengan melihat gambaran di atas, dapat dilihat atlet Jaya Raya butuh peningkatan keterampilan mental pada aspek self talk dan mental imagery.

Berikutnya, ketiga keterampilan mental di bawah ini dibutuhkan saat pertandingan berhadaphadapan dengan lawan, dengan hasil sebagai berikut..

7. Mengelola Kecemasan (Dealing with Anxiety)

Atlet yang mampu mengelola kecemasan adalah mereka yang menerima kecemasan sebagai bagian pertandingan dan tahu cara menurunkannya. Dapat dilihat bahwa mereka dengan kemampuan cukup dan kurang jumlahnya lebih banyak dibandingkan dengan mereka yang berkemampuan baik.

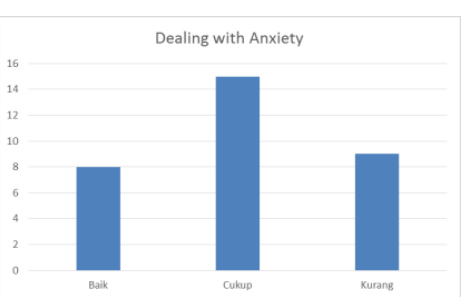

\section{Gambar 12. Mengelola Kecemasan}

8. Mengelola Emosi (Dealing with Emotion)

Atlet yang mampu mengelola emosi adalah mereka yang menerima emosi, mengungkapkan secara tepat dan menggunakan emosi untuk meningkatkan performa. Tabel di bawah menunjukkan mereka dengan kemampuan baik setara dengan mereka yang memiliki kemampuan kurang.

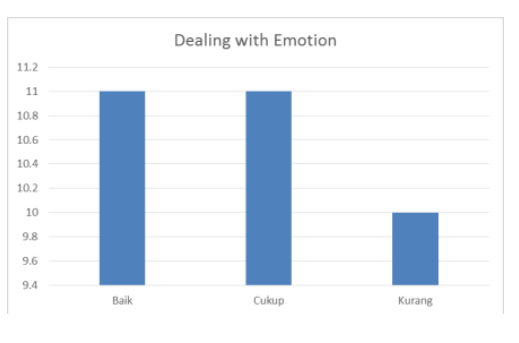

\section{Gambar 13. Mengelola Emosi}

9. Berkonsentrasi (Concentration)

Atlet yang mampu berkonsentrasi baik adalah mereka yang sanggup mempertahankan fokus selama bertanding. Sebagian besar memiliki kemampuan fokus yang baik. 


\section{Gambar 14. Konsentrasi}

Dari uraian di atas, maka secara umum, atlet PB Jaya Raya memiliki keterampilan psikologis yang cukup, sebagaimana tampak pada Gambar 15 berikut ini.

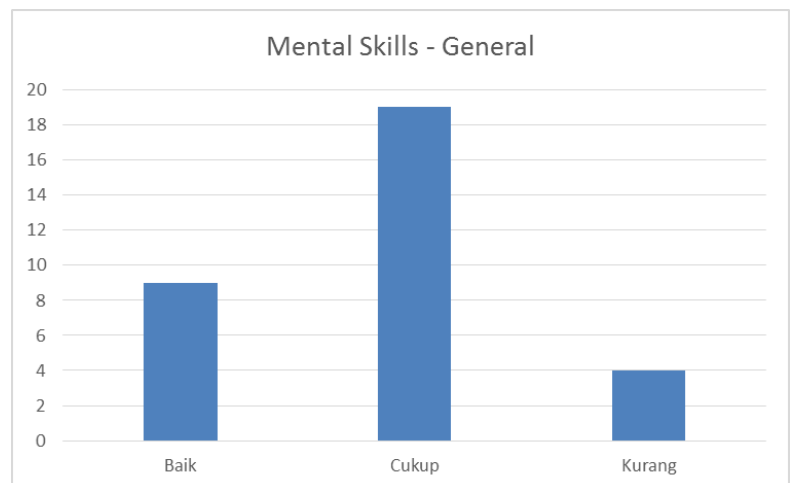

\section{Gambar 15. Gambaran Umum Keterampilan Psikologis}

\section{KESIMPULAN}

Temuan pengabdian masyarakat menyimpulkan bahwa keterampilan psikologis atlet PB Jaya Raya berada yang cukup. Pengabdian masyarakat ini menyarankan peningkatan kapasitas khususnya pada aspek self talk dan mental imagery, yang diharapkan nantinya berkontribusi pada dealing with anxiety.

Ucapan terimakasih diberikan kepada PB Jaya Raya, dimana sejak Maret 2017 kolaborasi PB Jaya Raya-PSI UPJ ini dipayungi MoU (Memorandum of Understanding) tingkat universitas dan MoA (Memorandum of Agreement) tingkat program studi. Ucapan terimakasih juga diberikan pada Lembaga Penelitian dan Pengabdian Masyarakat (LPPM UPJ) atas dukungan hibah Ipteks Bagi Masyarakat selama durasi 6 bulan, termasuk juga untuk dukungan hibah Penelitian Unggulan Perguruan Tinggi yang digunakan untuk menindaklanjuti saran dari pengabdian masyarakat ini.

Pengabdian masyarakat ini tidak hanya menghasilkan program konseling, tetapi juga publikasi 3 (tiga) artikel di media elektronik Info Bintaro 29 Agustus 2017 dan Buletin Konsorsium Psikologi Ilmiah Nusantara 10 Oktober 2017 dan 21 Januari 2018, 1(satu) publikasi Jurnal Widyakala UPJ Vol 4 No 1 Tahun 2017 yang kesemuanya digunakan sebagai referensi tulisan ini. Selain itu, pengabdian masyarakat ini juga menghasilkan 1 Modul Konseling untuk Atlet sebagai buku ber-ISBN dan poster Mental Skills untuk Atlet Jaya Raya - keduanya dilindungi di bawah pengakuan hak kekayaan intelektual (HKI).

\section{DAFTAR PUSTAKA}

1. Wondowisnowo, B.H. 2016. 40 tahun PB Jaya Raya Tak Pernah Henti Lahirkan Juara, Jakarta: Yayasan Pembangunan Jaya Raya.

2. Kompas. 2016. PB Jaya Raya Ingin Kejar Ketinggalan. 15 September. [http://olahraga.kompas.com/read/2016/09/15/17292751/pb.jaya.raya.ingin.kejar.ketertin ggalan]

3. Gunarsa, S. D. 2008. Psikologi Olahraga Prestasi. Jakarta: PT BPK Gunung Mulia. 
4. Putri, D. 2016. Gambaran Penerapan Managing Anxiety pada Atlet Tunggal Taruna di Klub Bulutangkis "XYZ” Universitas Pembangunan Jaya: Skripsi.

5. Soerjoatmodjo, G.W.L., Moningka, C. \& Angkawijaya, Y.F. 2018. Juara Juga Manusia. Buletin Konsorsium Psikologi Ilmiah Nusantara Vol 3 No 21 Januari 2018 [http://buletin.k-pin.org/index.php/arsip-artikel/228-juara-juga-manusia].

6. Williams, J.M. \& Straub, W.F. 2010. Sport Psychology: Past, Present, Future New York: McGraw-Hill.

7. Soerjoatmodjo, G.W.L., Kaihatu, V. Moningka, C. \& Angkawijaya, Y.F. 2017. Prospek Kebutuhan Layanan Psikologis untuk Atlet Jaya Raya. Widyakala. Volume 4 No 1 Maret 2017. hlm 11-20.

8. Widiani, H. (2011). Sumber Stres dan Strategi Coping pada Pelajar Atlet Bulutangkis. Fakultas Psikologi Universitas Islam Negeri Syarif Hidayatullah Jakarta: Skripsi.

9. Bulutangkis.com. 2016. PB Jaya Raya Bangun Fasilitas Pelatihan Baru di Bintaro. 14 September [http://www.bulutangkis.com/mod.php?mod=publisher\&op= viewarticle\&artid=103466]

10. Santrock, J.W. 2011. Life-Span Development. $14^{\text {th }}$ Edition. New York: McGraw-Hill

11. Rana, M.S. 2012. Assessment of Physiological Variables of Badminton Players, International Journal of Behavioral Social and Movement Sciences Vol. 01, Issue 04, Okt.hlm. 45-59

12. Soerjoatmodjo, G.W.L., Moningka, C. \& Angkawijaya, Y.F. 2017. Membangun Mental Juara. Info Bintaro. 29 Agustus [https://www.infobintaro.com/membangun-mentaljuara/]

13. Anderson, A.G., Miles, A., Mahoney, C. \& Robinson, C. 2002. Evaluating the Effectiveness of Applied Sport Psychology Practice: Making the Case for a Case Study Approach. The Sport Psychologist. Vol. 16 No. 4. hlm. 432-453

14. Anshel, M.H. 2003. Sport Psychology: From Theory to Practice. $4^{\text {th }}$ Edition San Fransisco: Pearson Education.

15. Thompson, C.L. Rudoph, L.R. \& Henderson, D.A. 2004. Conselling Children. $6^{\text {th }}$ Edition. California: Brooks/Cole-Thomson Learning

16. Moningka, C. 2017. Life Skills untuk Atlet di Indonesia . Buletin Konsorsium Psikologi Ilmiah Nusantara Vol 3 No 10 Oktober 2017 [http://buletin.k-pin.org/index.php/daftarartikel/201-life-skills-untuk-atlet-di-indonesia]

17. Giles, D. 2008. Advanced Research Methods in Psychology New York: Routledge, 2008.

18. Beebe, J. 2001. Rapid Assessment Process: An Introduction Oxford: AltaMira Press.

19. Lesyk (2007). The Nine Mental Skills of Successful Athletes: A Holistic Model for Assessing and Teaching Mental Skills to Athletes. Sport Psychologist. Vol 11. hlm.1-6 